\title{
Cultural Disadvantage or Special Needs? Deficit Thinking in Diagnosis and Placement for Special Education Students
}

\author{
Chiao-ling Yang \\ National Kaohsiung Normal University, Taiwan
}

\begin{abstract}
This study aims to examine how diagnosis and placement of special education students in elementary school embed deficit thinking. Its importance cannot be overstated as deficit thinking remains widespread and deep-rooted not only in education but also in daily lives, hindering equal opportunity of educational and social justice. This article focuses on the way in which special education students have been identified, diagnosed and placed since their early educational career, the elementary school level. To the extent that special education is expected to facilitate equality of educational opportunity and social justice, it is imperative that the process and result of school children placement be scrutinized to see if inequity of class, race, and gender is reproduced or reduced and how.
\end{abstract}

Keywords: class, race, and gender; cultural disadvantage; equality of educational opportunity; social justice; special education 


\section{Objectives or purposes}

This study aims to examine how the policy and practice of diagnosis and placement of special education students in elementary school embed deficit thinking. Its importance cannot be overstated as deficit thinking remains widespread and deep-rooted not only in education but also in daily lives (Brown, 2007; Pearl, 1997; Radnor, Koshy, \& Taylor, 2007; Whitty, 2001), hindering equal opportunity of educational and social justice (Ford \& Grantham, 2003; Gillborn, 2010).

The construct of deficit thinking, according to Valencia (1997, 2010), equals to a process of victim-blaming, a model based on imposition rather than verification, and its variant includes deficiency approach, deficit theories, deficit model. A relatively new label 'at risk' emerged in 1990s as a version of the cultural deficit model (Franklin, 2000; Swadener \& Lubeck, 1995). Regardless of the names, their common logic goes like this: students' failure in school is due either to their inherent deficit (be it cognitive or/and motivational) or to dysfunctional family and deficient culture, and thus exempts school organization, educational policy, and societal inequity from responsibilities. Such logic has heretofore been adopted by educators as well as policy makers with little, if any, doubt (McKenzie \& Phillips, 2016; Smit, 2012).

This article focuses on the way in which special education students have been identified, diagnosed and placed since their early educational career, the elementary school level. To the extent that special education is expected to facilitate equality of educational opportunity and social justice, it is imperative that the process and result of school children placement be scrutinized to see if inequity of class, race, and gender is reproduced or reduced and how.

\section{Perspective(s) or theoretical framework}

The aim of this study fits the critical education tradition, devoted to revealing power relations and how inequity manifests itself in education, especially in a complicated way. This tradition calls us for looking at the world with the eyes of the oppressed to fight against the reproduction of oppressing ideological and institutional processes and forms, including schooling (Apple, Au 
\& Gandin, 2009). Scholars already criticized schools as a sorting machine through which students are classified, analyzed and arranged in accordance with labels such as deviance and difference imposed from the outside (Apple, 2004; Kirp, 1974; Spring, 1976).

Speaking of classifying and labeling students, nothing can be compared with special education. In Taiwan, the government promulgated The Special Education Act in 1984 identifying 11 categories of disabilities. In 1997 two of them, Personality Disorders and Behavior Disorders, were deleted while adding three, Severe Emotional Disorders, Autism, and Developmental Delays. Emotional/Behavioral Disorders replaced Severe Emotional Disorders in order to include Attention Deficit Hyperactivity Disorder 12 years later, and Cerebral Palsy entered in 2013, resulting in 13 categories (Legislative Yuan of the Republic of China, 2005). This very development seems to echo with some researchers considering disabilities as social construction, not simply as medical problems of individuals (e.g., Chang, 2007). As for giftedness/talents, 6 categories are instituted, Intelligence, Scholarship, Arts, Creativity, Leadership, and Other Areas (Laws \& Regulations Database of The Republic of China, n.d.).

Here shows a dilemma facing special education, to help and educate students with disabilities as early as possible but not to mark and harm them. On the other hand, it's still a challenge to carry out Article 41 of Special Education Act, stipulating that local authorities and schools should reinforce diagnosis procedures and counseling services for gifted students with special needs and economical/social disadvantages (Wu, 2011). Similar difficulties occurred elsewhere; Robinson and Campbell (2010) maintain that the elite group in the UK has been good at manipulating the school system for their children to gain access to Gifted and Talented (G and T) programs disproportionately, even if the criteria have shifted from achievement to potential, expanded from subject areas to arts. White (2006) concurs with them arguing that the redirection and expansion of the concept of $\mathrm{G}$ and $\mathrm{T}$ do little justice to social equity because the recognition of potential and aptitude often relies upon teachers recommendation, usually favoring students from higher class background. This paper intends to address such issues with respect to Taiwanese elementary schools. 


\section{Methods and Data sources}

This article derives from the second year of a 3-year research project, concentrating on the policy and practice of diagnosis and placement for students with special needs, which makes it necessary to find key informants in order to obtain insiders knowledge. With the consent of the gatekeepers, some civil servants were invited to participate in interviews, who work at Education Bureau in a southern city in Taiwan, responsible for affairs of relevant divisions and centers. 9 persons took part in 6 interviews, as 2 interviews consist of 2 and 3 interviewees respectively. Codes of research ethics are observed. Data sources contain interview transcripts and pertinent documents offered by research participants, such as Application Form for Diagnosis and Placement of Students with Special Needs.

\section{Results and/or substantiated conclusions or warrants for arguments/point of view}

Most participants reported that the city government complies with the central government's laws, such as Statute For Compulsory Education and its Guidelines, requiring normal class grouping. The procedure and its outcome has won people's trust in general. But this is not the case for special education even though Special Education Act and its concomitant regulations are followed by the city government as well. What ensues will be divided into the disabled and the gifted education to demonstrate how deficit thinking operates explicitly and implicitly in the examination and deployment of special education students in elementary schools.

(1) Deficit thinking in education for the disabled

A. The term of 'cultural inadequacy' is used in official documents as a criterion to prevent from the identification of learning disabilities.

Different interviewees mentioned the same central government's regulation about the assessment of learning disabilities, which defines what constitutes learning disabilities, ruling out causes from other disorders and environmental factors, which specify inadequacy of cultural stimulation and inappropriate teaching. The local government certainly must adhere to such regulation, but the practice is much more ambiguous and complicated. As an interviewee expressed: 
When children are identified as disabled, they can hardly escape from labeling. But labeling itself may not be a problem. What really matters is with what the label is associated. In a good way, the label simply means they need special help for learning. To the contrary, it may connote negative implications and even stigmatize.

Other participants were also concerned with the issue of how to characterize 'cultural inadequacy', since the law doesn't spell it out and thus leaves much room for interpretation. One of them explained with an instance,

A child whose mom came from Vietnam was sent to Special Education Students Diagnosis and Placement Counseling Committee, briefly called DPCC, for being suspected of learning disabilities. We as local government administrative representatives see this case as culturally disadvantaged and should be dismissed, but the professors in DPCC don't agree, insisting that this child receive special education services as early as possible for his sake.

What's noteworthy is twofold. First, the Disabilities and Giftedness Students Diagnosis Regulation was codified in 2002 and had undergone revision for three times, 2006, 2012, 2013. Why didn't the policy makers ever reflect on the suitability of the term, inadequacy of cultural stimulation? In the US, such terms as 'culturally disadvantaged' have become synonymous with poor children of color, since they were present in the early 1960s in the early childhood literature (Swadener, 1995). What do such terms conjure up in contemporary Taiwanese society? We cannot afford not to reconsider such issues seriously as this nation has been getting more diverse culturally.

Secondly, most participants seem to endorse the usage, like the interviewee mentioned above identifying the child of Vietnamese mother with cultural disadvantage. $\mathrm{He}$ is not alone. Another interviewee further believes the exclusive criterion, cultural 
inadequacy, benefits the disadvantaged, such as children from low income families and/or of new immigrant women, because they won't be categorized easily as learning disabilities. What's unexplained is, however, why the so-called disadvantaged are supposed to lack cultural stimulation. Ford and Grantham's (2003:217) comment on educators applies to policy makers and governmental administrators as well, "Deficit thinking exists when educators hold negative, stereotypic, and counterproductive views about culturally diverse students and lower their expectations of these students accordingly."

B. The subjectivity inherent in assessment and diagnosis of psychological disorders makes deficit thinking have a role to play.

In contrast with physiological disorders diagnosed mainly by medical personnel, assessment of psychological disorders is performed usually by school educators and can rarely avoid subjective interpretation and judgement, which tends to put students from lower social backgrounds at a disadvantage. According to some research participants, elementary students won't be speculated as, for example, learning disabilities until their teachers propose. The reasons for teachers' suspicion pertain to either low achievement or behavioral problem, and both depend on teachers' perception, which is more or less influenced by deficit thinking. Even though trained professionals will screen the proposed students by testing their intelligence, it's still teachers' responsibility to collect both quantitative and qualitative data about students' performance as evidence for judgement. Neither is intelligence testing necessarily objective; like many scholars have noted that the tests measure familiarity with mainstream culture and language, not intelligence (Ford, Harris III, Tyson \& Trotman, 2001).

(2) Deficit thinking in gifted education

A. The official statistics shows neither aboriginal nor new immigrant women's children are in decentralized resource room for gifted education.

The Special Education Transmit (SET) Network presents different kinds of statistics, and all but two groups display both the disabled and the gifted. Children of 
aboriginal people and foreigners (mostly new immigrant women) are counted only for the disabled education (Ministry of Education, n.d.). I asked all interviewees about this absence, and some responses manifested deficit thinking. For example, one participant reasoned that those who live in rural areas and have children with intellectual disabilities lean to match their children with foreign brides from southeastern Asia nations, and their next generation's intellectual disabilities continue, and likewise, aboriginal children don't have enough cultural stimulation as they live in remote villages. Others acknowledged that, nonetheless, the testing instrument is prejudicial to both groups for its content always favors children from the mainstream culture, which appears to go beyond deficit thinking.

B. The familial or parental social background influences whether children will be sent for identification and placement of gifted education class.

While children of the disabled education range from upper-middle class to very poor families, most of the gifted children have parents with high social economic status. An interviewee observed that parents of upper-middle social class do have richer resources, including sending children to after-class schools, connecting with school educators such as principals. Others commented helplessly that some schools in rural and remote areas have stopped gifted education classes because very few students applied for examination and even fewer passed, given that the Act requests local authorities and schools to reinforce diagnosis procedures and counseling services for gifted students with special needs and economical/social disadvantages. The truth is the more metropolitan the schools locate, the more gifted students they have.

\section{Scientific or scholarly significance of the study or work}

The significance of this study is twofold. First, the ideal blueprint shaped by educational policies is inspected with evidence base. While excellence has been becoming a catchword in the field of education as international competition intensifies, even been opposed to equity (Robbins, 2007), OECD (2013) calls for excellence through equity or balancing both. To the extent that 
special education is instituted as a means for equal opportunity of education, it's important to investigate how deficit thinking may harm education of both the disabled and the gifted. The other lies in the attempt to disclose the contradiction of the school practice with both a critical analysis and a search for counter-discourse to redress the medical-psychological model dominant in special education in Taiwan for long (Chang, 2010).

\section{References}

Apple, M. W. (2004). Curriculum and ideology. Third edition. New York, NY: RoutledgeFalmer.

Apple, M. W., Au, W., \& Gandin, L.A. (2009). Mapping critical education. In M.A. Apple, W. Au, \& L. A. Gandin (eds.), The Routledge international handbook of critical education (pp. 3-19). New York, NY: Routledge.

Brown, E. (2007). The significance of race and social class for self-study and the professional knowledge base of teacher education. In J. J. Loughran, M. L. Hamilton, V. K. LaBoskey, \& T. Russell (eds.), International handbook of selfstudy of teaching and teacher education practices (pp. 517-514). Dordrecht, the Netherlands: Springer.

Chang, C. (2010). A sociological study of principals' perspectives on the definition of special educational needs (SEN) in Taiwan. Bulletin of Special Education, 35(2), 1-27.

Chang, H. (2007). Special education and sociology of disability: a theoretical reflection. Education and Society Studies, 13:71-94.

Ford, D. Y. \& Grantham, T. C. (2003). Providing access for culturally diverse gifted students: from deficit to dynamic thinking. Theory Into Practice, 42(3), 217-225.

Ford, D. Y., Harris III, J. J., Tyson, C. A., \& Trotman, M. F. (2001). Beyond deficit thinking: providing access for gifted African American students. Roeper Review, 24(2), 52-58.

Franklin, W. (2000). Students at promise and resilient: a historical look at risk. In M. 
G. Sanders (Ed.), Schooling students placed at risk: Research, policy, and practice in the education of poor and minority adolescents (pp. 3-16). New York, NY: Routledge.

Gillborn, D. (2010). The colour of numbers: surveys, statistics and deficit-thinking about race and class. Journal of Education Policy, 25(2), 253-276.

Kirp, D. L. (1974). The great sorting machine. Phi Delta Kappan, 55(8), 521-525.

Laws \& Regulations Database of The Republic of China. (n.d.). The Special

$\begin{array}{llll}\text { Education } & \text { Act. } & \text { Retrieved }\end{array}$ https://law.moj.gov.tw/ENG/LawClass/LawAll.aspx?pcode=H0080027

Legislative Yuan of the Republic of China. (2005). Special Education Law--Law

History-National Laws--Global Legal Information Network. Retrieved from https://glin.ly.gov.tw/web/nationalLegal.do?isChinese=false\&method=legal\&newQuery=tr ue\&legalTypeId=73\&fromWhere=legalType

McKenzie, K. B. \& Phillips, G. A. (2016). Equity traps then and now: deficit thinking, racial erasure and naïve acceptance of meritocracy. Whiteness and Education, $1(1), 26-38$.

Ministry of Education. (n.d.). Special Education Transmit Network. Retrieved from https://www.set.edu.tw/Stastic_WEB/sta2/default.asp?sec=6

OECD (2013). PISA 2012 Results: Excellence through equity: Giving every student the chance to succeed (Volume II), PISA, OECD Publishing. http://dx.doi.org/10.1787/9789264201132-en.

Pearl, A. (1997). Democratic education as an alternative to deficit thinking. In R. Valencia (ed.), The evolution of deficit thinking: Educational thought and practice (pp. 211-241). London: Falmer.

Radnor, H., Koshy, V. \& Taylor, A. (2007). Gifts, talents and meritocracy. Journal of Education Policy, 22(3), 283-299.

Robbins, L. (2007). Equity vs. excellence: is education still a zero-sum game? Peabody Reflector, 76(2), 3-6. 
Robinson, W. \& Campbell, J. (2010). Effective teaching in gifted education: Using a whole school approach. London: Routledge.

Smit, R. (2012). Towards a clearer understanding of student disadvantage in higher education: problematizing deficit thinking. Higher Education Research \& Development, 31(3), 369-380.

Spring, J. (1976). The sorting machine: National educational policy since 1945. New York, NY: David McKay Company.

Swadener, B. B. (1995). Children and families "at promise": Deconstructing the discourse of risk. In B. B. Swadener \& S. Lubeck (Eds.), Children and families "at promise”: Deconstructing the discourse of risk (pp. 17-49). New York, NY: State University of New York.

Swadener, B. B. \& Lubeck, S. (1995). The social construction of children and families "at risk": an introduction. In B. B. Swadener \& S. Lubeck (Eds.), Children and families "at promise": Deconstructing the discourse of risk (pp. 1-14). New York, NY: State University of New York.

Valencia, R. (ed.) (1997). The evolution of deficit thinking: Educational thought and practice (pp. ix-xvii). London: The Falmer.

Valencia, R. (2010). Dismantling contemporary deficit thinking: Educational thought and practice. New York, NY: Routledge.

White, J. (2006). Intelligence, destiny and education: The ideological roots of intelligence testing. London: Routledge.

Whitty, G. (2001). Education, social class and social exclusion. Journal of Education Policy, 16(4), 287-295.

Wu, W. (2011). The evolution and betterment of special education in Taiwan. In C. Wu, C. Wu, M. Wen \& other, The review and outlook of Taiwanese education for the past 100 years (pp. 199-220). New Taipei City, Taiwan: National Academy for Educational Research. 